\title{
OTOMATISASI SISTEM PENGISIAN BATERAI PADA SISTEM TENAGA SURYA
}

\section{AUTOMATION OF THE BATTERY CHARGING SYSTEM IN THE SOLAR POWER SYSTEM}

\author{
Yuli Prasetyo $^{1}$, Budi Triyono ${ }^{2}$, R. Jasa Kusumo H. ${ }^{3}$, Aditya Pradana P. ${ }^{2}$ \\ 1,2,3,4 Politeknik Negeri Madiun, Jl. Serayu No 84, Madiun, Jawa Timur, Indonesia.
}

E-mail: yuliprasetyo2224@pnm.ac.id

\begin{abstract}
ABSTRAK
Panel surya merupakan alat yang dapat menghasilkan energi listrik dari energi matahari. Penggunaan panel surya biasanya berkaitan dengan penggunaan baterai untuk penyimpan energi. Waktu pengisian yang singkat diinginkan dari sistem bertenaga baterai. Namun, waktu pengisian yang singkat juga harus memperhatikan keandalan sistem. Dimana waktu pengisian yang singkat tidak menyebabkan kerusakan pada sistem kendali dan baterai. Baterai memiliki peran penting sebagai sumber suplai tenaga saat matahari tidak cerah. Dengan meminimalisir waktu pengisian baterai, baterai dapat dimanfaatkan secara maksimal sebagai penyimpan tenaga. sehingga didapat waktu pengisian yang minimum, tetapi dengan daya penyimpanan yang maksimal. Kontrol pengisian baterai dengan metode pengisian cepat dan mematikan secara otomatis pada sistem ini dihadirkan dalam peneltian ini. Kontroler didasarkan pada skema kontrol muatan arus dan tegangan konstan (CCV). Untuk menjaga agar parameter tetap konstan, prototipe penelitian ini menggunakan pengontrol DC-DC tipe buck converter. Hasil eksperimen menunjukkan periode pengisian berkurang secara signifikan. Selain itu, pengontrol yang diusulkan memiliki akurasi tinggi dan mengurangi pengisian daya baterai yang berlebihan. Lampu indikator pada sistem pengisian baterai menyala saat proses pengisian dan lampu indikator padam saat proses pengisian baterai telah selesai atau baterai kondisi penuh.
\end{abstract}

Kata Kunci: Panel Surya, Overcharging Baterai, Buck Converter, Pengisian Baterai 


\begin{abstract}
Solar panels are devices that can produce electrical energy from solar energy. The use of solar panels is usually related to the use of batteries for energy storage. Short charging times are desirable from battery powered systems. However, the short charging time should also pay attention to the reliability of the system. Where the short charging time does not cause damage to the control system and battery. Batteries have an important role as a source of power supply when the sun is not bright. By minimizing the battery charging time, the battery can be utilized optimally as a power store. so that the minimum charging time is obtained, but with maximum storage power. Battery charge control with fast charging method on and off automatically in this system is presented. The controller is based on a constant current and voltage $(\mathrm{CCV})$ charge control scheme. To keep the parameters constant, this research prototype uses a buck converter type DC-DC controller. The experimental results show the charging period is significantly reduced. In addition, the proposed controller has high accuracy and reduces battery overcharging. The indicator light on the battery charging system lights up during the charging process and the indicator light goes out when the battery charging process is complete or the battery is full.
\end{abstract}

Keywords: Solar Panel, Battery Overcharging, Buck Converter, Battery Charging

\title{
PENDAHULUAN
}

Energi matahari merupakan energi yang terbarukan yang dapat digunakan oleh semua orang. Indonesia yang terletak di negara dengan iklim tropis maka akan memiliki energi matahari yang cukup melimpah. Penggunaan energi matahari ini sangat ramah lingkungan dan tidak menimbulkan polusi. Energi matahari ini juga dapat dirubah menjadi energi listrik [1], [2]. Alat yang digunakan untuk merubah energi matahari menjadi energi listrik adalah panel surya. Panel surya atau Photovoltaic (PV) adalah teknologi yang berfungsi untuk mengubah atau mengkonversi radiasi matahari menjadi energi listrik secara langsung. Dalam sebuah modul panel surya terdiri dari beberapa sel surya yang bisa disusun secara seri maupun paralel. Tegangan output yang dihasilkan dari panel surya merupakan tegangan DC [3], [4].

Pada sistem panel surya untuk menghasilkan energi listrik diperlukan beberapa peralatan atau komponen. Komponen yang digunakan dalam sistem panel surya berupa panel surya, baterai, sistem control, beban DC. Sistem panel surya ini juga dapat menghasilkan tegangan output AC. Untuk menghasilkan tegangan output $\mathrm{AC}$, maka sistem panel surya memerlukan inverter yang dapat mengubah tegangan DC menjadi tegangan AC. Sehingga sangat dimungkinkan untuk membuat suatu sistem power station yang berasal dari energi matahari. 
Penggunaan panel surya biasanya berkaitan dengan penggunaan baterai untuk penyimpan energi. Waktu pengisian yang singkat diinginkan dari sistem bertenaga baterai. Namun, waktu pengisian yang singkat juga harus memperhatikan keandalan sistem [5], [6]. Dimana waktu pengisian yang singkat tidak menyebabkan kerusakan pada sistem kendali dan baterai. Baterai memiliki peran penting sebagai sumber suplai tenaga saat matahari tidak cerah. Dengan meminimalisir waktu pengisian baterai, baterai dapat dimanfaatkan secara maksimal sebagai penyimpan tenaga [7], [8]. sehingga didapat waktu pengisian yang minimum, tetapi dengan daya penyimpanan yang maksimal [9]. Oleh karena itu penelitian ini memiliki fokus pada otomatisasi sistem pengisian baterai sehingga dapat menambah umur baterai dan meminimalkan terjadinya overcharging.

\section{METODE PENELITIAN}

\section{Panel Surya}

Panel surya adalah alat yang dapat mengkonversi energi matahari menjadi energi listrik. Panel surya atau Photovoltaic (PV) adalah teknologi yang berfungsi untuk mengubah atau mengkonversi radiasi matahari menjadi energi listrik secara langsung. Dalam sebuah modul panel surya terdiri dari beberapa sel surya yang bisa disusun secara seri maupun paralel. Contoh alat panel surya sesuai dengan gambar 1 .

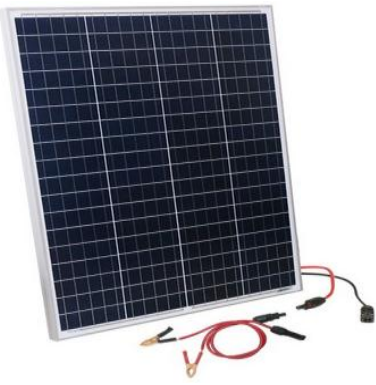

Gambar 1. Panel Surya

\section{Buck Converter}

Buck converter merupakan konverter penurun tegangan khusus yang menerapkan sistem SMPS (Switching Mode Power Supply). Buck converter dapat memanfaatkan sifat induktor terhadap guncangan listrik berfrekuensi tinggi dan bekerja dengan adanya denyut tegangan (sebagaimana layaknya SMPS). Sebuah rangkaian buck converter di dalamnya selalu terdapat generator sinyal, transistor penguat, dioda, kondensator dan induktor seperti ditunjukkan pada gambar 2 .

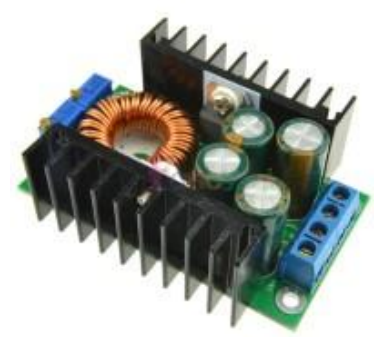

Gambar 2. Buck Converter

\section{Voltage Regulator}

Voltage Regulator atau Pengatur Tegangan merupakan salah satu rangkaian yang sering dipakai di peralatan Elektronika. Fungsi Voltage Regulator adalah untuk mempertahankan atau memastikan Tegangan 
pada level tertentu secara otomatis. Artinya, Tegangan Output (Keluaran) DC pada Voltage Regulator tidak dipengaruhi oleh perubahan tegangan input (masukan), Beban pada output dan juga suhu. Tegangan stabil yang bebas dari segala gangguan seperti noise ataupun fluktuasi (naik turun) sangat dibutuhkan untuk mengoperasikan peralatan elektronika. Gambar 3 menunjukkan bentuk dari alat voltage regulator.

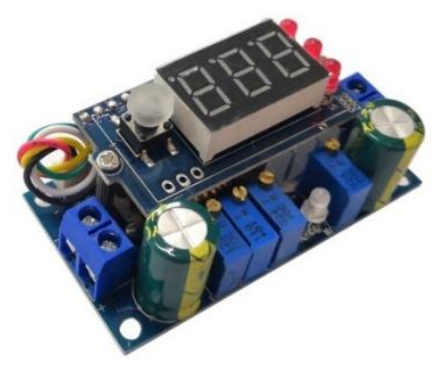

Gambar 3. Voltage Regulator

\section{Skema Penelitian}

Skema penelitian dibuat bertujuan untuk memudahkan pembaca mengenai proses dari kerja sebuah alat penelitian ini. Pada gambar 4 dijelaskan bahwa sumber tegangan dari panel surya dan baterai. Sedangkan untuk output berupa beban DC dan beban AC. Beban DC seperti lampu LED, kipas DC dll. Beban AC dapat berupa kipas angin, TV, Laptop dll.

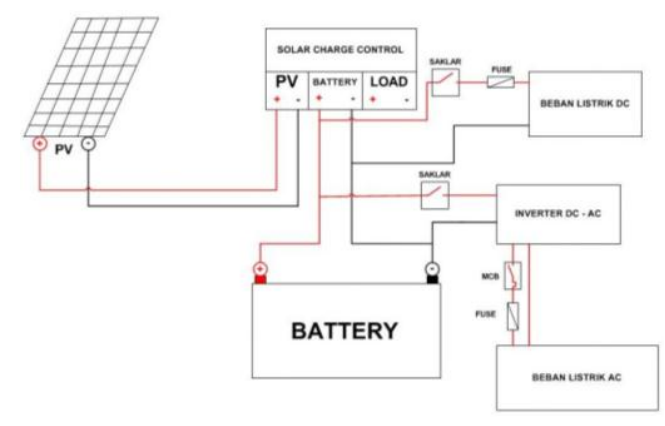

Gambar 4. Skema Penelitian

\section{HASIL PENELITIAN DAN PEMBAHASAN}

Tahap hasil dan pembahasan dilakukan beberapa pengujian pada sistem untuk memperoleh data.

\section{1) Hasil Pengujian Panel Surya}

Pada proses pengujian panel surya dilakukan untuk mengetahui nilai tegangan output pada panel surya. Panel surya yang digunakan memiliki spesifikasi yaitu 100WP. Tegangan output ini yang akan digunakan sebagai input sistem pengisian baterai pada sistem panel surya. Pengujian tegangan output panel surya seperti pada gambar 5 . Pengujian panel surya dilakukan dari jam 9 pagi sampai jam 14 siang. Hasil pengujian panel surya seperti pada tabel 1. Tegangan output yang dihasilkan panel surya memiliki tegangan DC dan sangat bervariasi. Faktor cuaca atau kondisi cuaca yang tidak cerah menyebabkan tegangan output panel surya menjadi lebih kecil. Kondisi panel surya yang tertutup sesuatu benda juga dapat menyebabkan tegangan output menjadi berkurang.

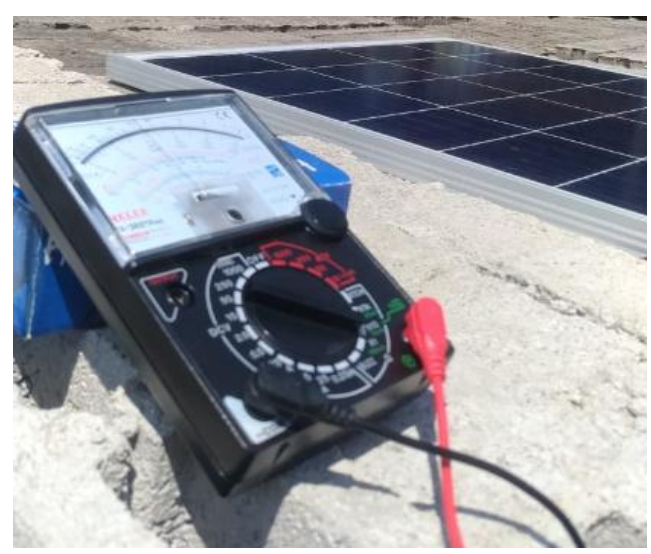

Gambar 5. Pengujian Panel Surya 
Tabel 1. Hasil Pengujian Panel Surya

\begin{tabular}{ccc}
\hline No & Time & Output Voltage $(\mathrm{V})$ \\
\hline 1 & 09.00 & 13.5 \\
2 & 09.30 & 13.5 \\
3 & 10.00 & 13.0 \\
4 & 10.30 & 14.0 \\
5 & 11.00 & 14.4 \\
6 & 11.30 & 14.4 \\
7 & 12.00 & 14.8 \\
8 & 12.30 & 14.8 \\
9 & 13.00 & 14.5 \\
10 & 13.30 & 14.5 \\
11 & 14.00 & 13.2 \\
\hline
\end{tabular}

\section{2) Hasil Pengujian Sistem Control}

Proses pengujian selanjutnya adalah pengujian sistem control buck converter. Pengujian ini dilakukan untuk melihat tegangan output pada buck converter. Gambar 6 menunjukkan gambar rangkaian buck converter. Hasil tegangan output dari buck converter dapat terlihat pada gambar 7 .

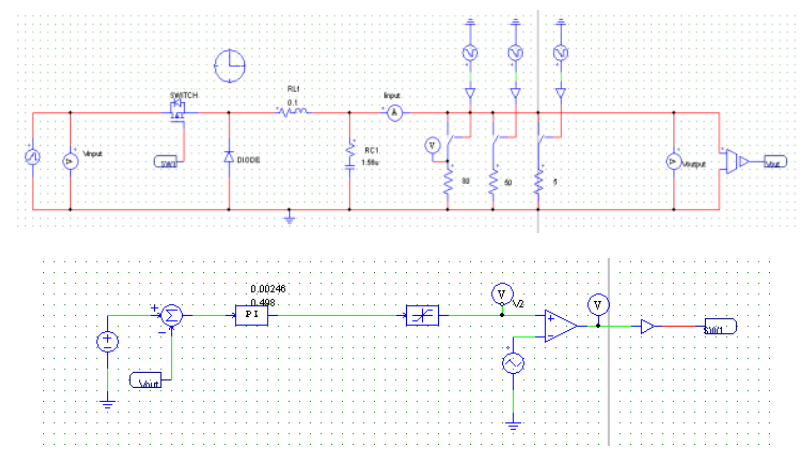

Gambar 6. Rangkaian Buck Converter

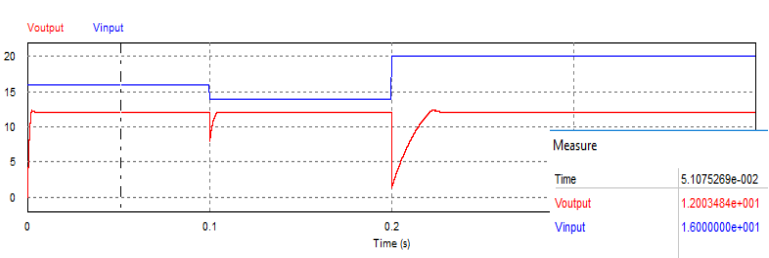

Gambar 7. Hasil Tegangan Output Buck Converter
Hasil pengujian tegangan output buck converter menunjukkan bahwa tegangan output buck converter dapat tetap konstan sesuai dengan tegangan yang diinginkan. Perubahan pada tegangan input buck converter tidak mempengaruhi tegangan output pada buck converter. Hal ini menunjukkan bahwa jika terjadi perubahan pada tegangan output panel surya maka tegangan output buck converter akan tetap konstan.

\section{3) Hasil Pengujian Sistem Charging}

Hasil pengujian berikutnya dari sistem pengisian baterai atau sistem charging baterai. Baterai yang digunakan memiliki kapasitas $\begin{array}{llll}\text { tegangan } & \text { sebesar } 12 \mathrm{Vdc} \text { Gambar } 8\end{array}$ menunjukkan sistem charging baterai saat terjadi pengisian baterai. Saat terjadi proses pengisian baterai maka lampu indikator pada sistem charging akan menyala. Sedangkan jika baterai dalam kondisi penuh atau tidak dalam kondisi pengisian baterai maka lampu indicator pada sistem charging akan padam. Hal ini menunjukkan sistem charging dapat dengan otomatis melakukan pengisian dan pemutusan pengisian baterai. Sehingga kondisi baterai tidak akan mengalami overcharging atau kelebihan tegangan pengisian yang dilakukan terus menerus. Gambar 9 menunjukan kondisi saat sistem charging dapat memutus pengisian baterai. Data hasil pengujian sistem charging dapat dilihat pada tabel 2. Tegangan pada proses 
pengisian baterai akan lebih tinggi dibandingkan dengan tegangan nominal pada baterai. Jika tegangan sistem charging sudah sesuai dengan tegangan nominal baterai maka tidak akan ada arus pengisian baterai yang mengalir dan berarti baterai dalam kondisi penuh. Hasil penelitian menunjukkan periode pengisian berkurang secara signifikan. Selain itu, pengontrol yang diusulkan dapat mengurangi pengisian daya baterai yang berlebihan.

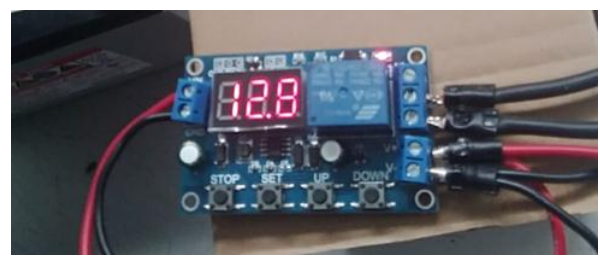

Gambar 8. Tegangan Sistem Charging Saat Pengisian Baterai

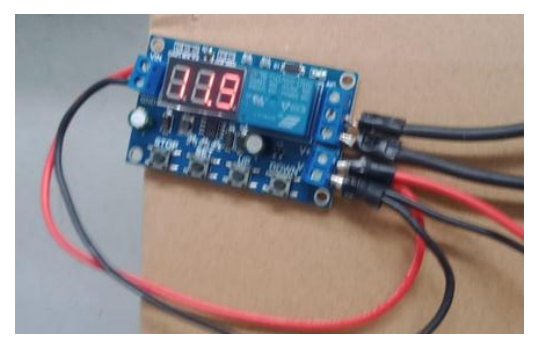

Gambar 9. Tegangan Sistem Charging Saat Baterai Kondisi Penuh
Tabel 2. Hasil Pengujian Sistem Charging

\begin{tabular}{ccc}
\hline $\begin{array}{c}\text { Tegangan } \\
\text { Charging (V) }\end{array}$ & $\begin{array}{c}\text { Tegangan Alat Kondisi Lampu } \\
\text { Ukur (V) }\end{array}$ & \begin{tabular}{c} 
Indikator \\
\hline 13.1
\end{tabular} \\
13.1 & 13.00 & On \\
13.0 & 12.96 & On \\
12.9 & 12.87 & On \\
12.9 & 12.81 & On \\
12.8 & 12.77 & On \\
12.8 & 12.70 & On \\
11.9 & 12.00 & Off \\
\hline
\end{tabular}

\section{KESIMPULAN}

Penelitian ini telah berhasil membuat rancang bangun sistem pengisian baterai otomatis dari sumber panel surya. Teknik yang diusulkan dapat mengontrol tegangan yang diterapkan pada konverter DC - DC. Hal tersebut dapat dilihat dari hasil percobaan saat lampu indikator sistem pengisian padam dan proses charging akan otomatis berhenti ketika tegangan baterai telah tercapai yaitu $12 \mathrm{Vdc}$. Jika lampu indicator masih menyala maka proses pengisian akan terus berlanjut hingga didapatkan nilai tegangan sesuai set point yaitu $12 \mathrm{Vdc}$.

\section{DAFTAR PUSTAKA}

[1] Y. Prasetyo, B. Triyono, and H. Kusbandono, "Dual Axis Solar Tracker Using Astronomic Method Based Smart Relay," JAREE J. Adv. Res. Electr. Eng., vol. 5, no. 1, Apr. 2021, doi: 10.12962/jaree.v5i1.156.

[2] B. Triyono, Y. Prasetyo, and H. Kusbandono, "Optimasi Output Dual Axis Solar Tracker Menggunakan Metode Astronomi Berbasis Smart Relay,” Transmisi, vol. 23, no. 1, pp. 1-4, Jan. 2021, doi: 10.14710/transmisi.23.1.1-4. 
[3] Y. Prasetyo, B. Triyono, H. Kusbandono, and A. T. A. Salim, "Optimization of Solar Panel Output Using Smart Relay,” vol. 5, no. 4, p. 3.

[4] Y. Prasetyo, B. Triyono, and A. C. Arifin, "Optimalisasi Daya Output Dual Axis Solar Tracker Dengan Metode Umbrella System,” vol. 02, no. 02, p. 8, 2019.

[5] S. Triwijaya, N. Sugiantoro, Y. Prasetyo, Firdaus, R. S. Wibowo, and O. Penangsang, "Security Constrained Optimal Power Flow Considering Dynamic Line Rating," in 2018 10th International Conference on Information Technology and Electrical Engineering (ICITEE), Kuta, Jul. 2018, pp. 46-51. doi: 10.1109/ICITEED.2018.8534755.

[6] S. Triwijaya and Y. Prasetyo, "Pengaturan Batas Keamanan Sistem Aliran Daya Optimal Dc Menggunakan Metode Quadratic,”vol. 03, no. 012, p. 7, 2020.

[7] B. Triyono and Y. Prasetyo, "Multi Input Energi Terbarukan Pada Sistem De Bus Menggunakan Buck Boost Converter," vol. 02, no. 01, p. 8, 2019.

[8] Y. Prasetyo, B. Triyono, and H. Kusbandono, "Penerapan Smart Relay Untuk Penentuan Posisi Sudut Panel Surya Dengan Metode Astronomi," JEECAE J. Electr. Electron. Control Automot. Eng., vol. 5, no. 2, pp. 39-41, Nov. 2020, doi: 10.32486/jeecae.v5i2.624.

[9] Y. Prasetyo, B. Triyono, H. N. K. Ningrum, R. J. K. Haryo, N. A. H., and W. Muchsin, "Penerapan Automatic Transfer Switch Pada Sistem Irigasi Di Desa Rejosari Kabupaten Madiun,” JATI EMAS J. Apl. Tek. Dan Pengabdi. Masy., vol. 4, no. 2, p. 99, Nov. 2020, doi: 10.36339/je.v4i2.313. 